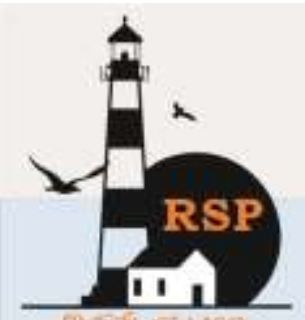

\title{
Analysis of Heat Reduction through Technique Roof Using Innovative Insulation Technique
}

R. Rajavel, ${ }^{1}$. A.Makudesh Arjun Kumar ${ }^{2}$, N.C.K. Amaranath ${ }^{3}$, Harishkumar, $J^{4}$. Mahendran ${ }^{5}$

${ }^{1}$ Assistant Professor, Department of Mechanical Engineering, Mahendra Institute of Engg and Tech, Namakkal, Tamilnadu, India

${ }^{2} U G$ Scholar, Aeronautical Engineering, Mahendra Institute of Engineering and Technology, Namakkal, Tamilnadu, India.

${ }^{3}$ UG Scholar, Agriculture Engineering, Mahendra Institute of Engineering and Technology, Namakkal, Tamilnadu, India

${ }^{4} U G$ Scholar, Petro Chemical Engineering, Mahendra Institute of Engineering and Technology, Namakkal, Tamilnadu, India.

${ }^{5}$ UG Scholar, Mechanical Engineering, Mahendra Institute of Engineering and Technology, Namakkal, Tamilnadu, India.

\begin{abstract}
Buildings have a significant and continuously increasing impact on the environment. The power consumption for comfortable housing is ever increasing, which is adding additional burden to the power crisis of the world. The main objective of this project is to reduce the heat transfer through the building roof by providing thermal insulation, thereby reducing the heat load on the building. Moreover, if the building is to be air-conditioned then effective thermal insulation will reduce the power consumption drastically and saves lot of energy consumption. New innovative type of insulation is proposed in this work to reduce the heat transfer through roof structure by using seashells and coconut shells. The coconut shells and seashells layer along with normal tiles will provide very good thermal insulation and it will maintain low roof bottom surface temperature when compared with the normal conventional concrete roof without insulation. Two identical experimental rooms were constructed on the top of the college mechanical engineering department block and were instrumented with thermocouple and RTD along with data logger for obtaining continuous experimental results. The amount of heat reduction provided by the insulated roof structure was calculated using the analytical method. Then the cooling load requirement for airconditioning and the corresponding energy cost per year was calculated for the new CAD lab of the mechanical engineering department. The result showed the huge energy savings potential for this innovative thermal insulation technique. The electricity savings obtained is around 39.7\%. when compared with the conventional concrete roof. This innovative technique for providing thermal insulation to the building is more affordable and comfortable for living.
\end{abstract}

\section{Introduction}

Buildings have long been recognized as one of the most important man-made built structures imposing significant impact on both local and global environments. The original purpose of a building is to provide shelter and to maintain a comfortable internal temperature. Buildings have an enormous and continuously increasing impact on the environment, using about $40 \%$ of natural resources extracted in industrialized countries, 


\section{www.rspsciencehub.com}

consuming nearly $70 \%$ of electricity and $12 \%$ of portable water. Buildings also consume a considerable proportion of raw materials globally and produce a significant amount of wastes during their construction and demolition process. The wastes generated by building construction and demolition processes accounted for half of the total amount of municipal solid waste generated in the same year. Buildings accounted for more than 20$40 \%$ energy consumption in developed countries. Moreover they are responsible for a large amount of harmful emissions, accounting for $30 \%$ of greenhouse gases due to their operation and an additional $18 \%$ caused indirectly by material exploitation and transportation. At the same time the bad quality of indoor environments may cause health problems to employees in office buildings, thus decreasing productivity.[1,2] Heat entering into the building structure through roof is the major cause for discomfort in case of non-air-conditioned building or the major load for the air-conditioned building. Efforts generally focused on single issues such as energy efficiency and conservation of natural resources in the course of striving for environmental excellence.

\section{Green buildings}

According to IGBC (Indian green building council), a green building is one which uses less water, optimizes energy efficiency,[3-5] conserves natural resources, generates less waste and provides healthier spaces for occupants, as compared to a conventional building. Green building is a way of enhancing the environment. It benefits humans, the community, the environment, and a builder's bottom line. It is about tailoring a building and its site to the local climate, site conditions, culture and community, in order to reduce resource consumption while enhancing quality of life. A green building incorporates design, construction and operational practices that significantly reduce or eliminate its negative impact on the environment and its occupants. Building green is an opportunity to use resources efficiently while creating healthier environments for people to live and work in. Green building can also significantly reduce construction and performance costs.

\section{Literature Review}

Zhai et al. proposed that the modern comfort living conditions are achieved at the cost of vast energy resources. Global warming and ozone depletion and the escalating costs of fossil fuels over the last few years, have forced governments and engineers to re-exam in the whole approach to the design and control of building energy system. Consequently, it is of great importance in the building field to reconsider the building structure and exploit renewable energy systems, which can minimize the energy expenditure and improve thermal comfort. Solar energy is abundant and clean; it is meaningful to substitute solar energy for conventional energy. Solar energy therefore has an important role to play in the building energy system. The ways solar systems are used in newer buildings usually combine several solar-related technologies. They may be both solar heated/cooled and solar powered, i.e. they are simply solar buildings. Recently, solar water collectors have undergone a rapid development; they are installed with the main purpose of preheating domestic hot water and/or to cover a fraction of the space heating demand. However, this application mainly for obtaining hot water through solar energy is not very consistent with the order of nature. In winter, it is convenient to combine hot water system with space heating system just through increasing the collector area. Whereas, for summer with high solar radiant intensity and high ambient air temperature, the demand for air-conditioning and refrigeration is in preference to hot water, this phenomenon is obvious especially in the south of China for example. The prevalence of air-conditioners has brought great pressure upon energy, electricity and environment. Consequently, solar-powered air-conditioning system would be a perfect scheme because it not only makes the best use of solar energy, but also converts low-grade energy (solar energy) into highgrade energy for comfort. In addition, it is meaningful for the energy conservation and environment protection. Solar cooling has been shown to be technically feasible. Vijay kumar et al. done an investigation on a performance of hollow clay tile (HCT) laid reinforced cement concrete (RCC) roof for tropical summer climates [10]. He explained that most of the Indian concrete buildings have $150 \mathrm{~mm}$ thick reinforced cement concrete (RCC) with weathering course (WC) having 75$100 \mathrm{~mm}$ thick lime brick mortar. Such roofs account for about $40-75 \%$ of total heat transmitted into the 
occupant zone depending upon the location and also account for the major portion of electricity bill in air-conditioned buildings. A new concept where in hollow clay tiles (HCT) are laid over RCC instead of $\mathrm{WC}$ has been proposed. The transient heat transmission across various types of roof structures for typical Indian climatic conditions has been studied. The energy savings obtained with the use of HCT roof is found to be 38-63\% when compared with conventional WC roof. When air is allowed to flow through the hollow passages, the air flow is found to take care of all variations in the outside climate and solar radiation, thus providing almost uniform roof bottom surface temperature Due to lower thermal mass and considerable thermal conductivity of bare concrete roof (Roof-1), heat entering the room is higher and the roof is more sensitive to solar heat flux variation. About $50 \%$ reduction in heat transmission is noticed by laying weathering course (Roof-2) over concrete roof. Very low thermal conductivity of air, blocks most of the heating case of Roof-3, resulting in $70 \%$ reduction of heat entering into the room. The air flow through the hollow passage roof-4is found to remove the major portions of heat entering into the roof top.

Even though the time lag is same as Roof-2, but decrement factor of Roof-3 will be only half of Roof-2, i.e., the ratio between magnitude of heat flux entering through the roof and heat flux at the roof top is equal to 0.02 (whereas for weathering course, it is 0.04$) \mathrm{v}$. When compared to conventional weathering course roof(Roof-2), Roof-3 and Roof4 are found to reduce the heat entering into the room by about 38 and $63 \%$, respectively. Thus, the Roof4 , i.e., reinforced cement concrete with hollow clay tile (open passage) combination is the preferred choice for tropical summer climates. Tahir Ayata et al. carried out an investigation of sensible heat fluxes at a green roof in a laboratory setup.

In the overall heat transfer at green roof assemblies, sensible heat fluxes have a very important role, especially at the low volumetric water content (dry soil) conditions in addition to the latent heat fluxes. However, direct calculations of sensible heat fluxes and definition of a calculation method is challenging because green roofs have additional parameters, which significantly affect the convective heat fluxes when compared to a rectangular smooth or rough plates.

These parameters change the thermal behavior of green roofs. Effects of these parameters must be understood for accurate calculations of sensible heat fluxes. Many experimental and theoretical studies examined the thermal behavior of green roofs for the outdoor environmental weather conditions. Laboratory studies were also conducted with sample plant or plants under controlled environmental conditions. Firstly, sensible heat fluxes were calculated from the energy balance at the green roof assembly. Secondly, a proposed modified. Newton's law equation called the "basic model", as well as the Logarithmic Wind Profile model, and McAdams' model were used for sensible heat flux calculations for free and forced convection conditions. Thirdly, a rearranged form of the "basic model" was selected for further improvements due to its consistent performance in both free and forced convection conditions.

The inverse ratio between the volumetric water content and sensible heat flux was observe enduring the laboratory measurements. This relation was used to rearrange the basic sensible heat flux calculation method for forced and free convection conditions. Effects of wind velocity and temperature difference were also considered. Equations give the newly proposed form of Newton's cooling law for calculation of sensible heat fluxes to/from a green roof. A good agreement was observed between the calculated and measured sensible heat fluxes. For the forced convection flow regimes, the convective heat flux calculations with the proposed "basic model" resulted in an average RMSE and R2 values of $11 \mathrm{~W} / \mathrm{m} 2$ and 0.81 , respectively. Similarly, the proposed basic sensible heat flux model provided good RMSE $(6.6 \mathrm{~W} / \mathrm{m} 2)$ and R2 (0.90) values for sensible heat flux with free convection conditions.

\section{Methodology}

The amount of heat transferred into building decides the power requirement for the air conditioning. If the infiltration of heat into the building through the roof can be reduced corresponding power consumption for air- 


\section{www.rspsciencehub.com}

conditioning can be reduce and there is huge saving in electricity cost. Thus the project aims to reduce the amount of heat transferred in to the building through the roof. The main focus of the project is to reduce the heat transfer from building roof by utilizing naturally available, reliable, cost effective materials. In this work seashells and coconut shells are used innovatively for insulation. The roof structure used us for our investigation is described below.

\section{Modelling of conventional and insulated roof:}

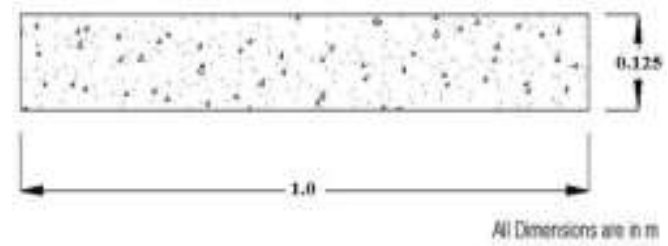

Fig.1. The roof model used for the analysis

The roof model used for the analysis is shown in fig1. Conventional Reinforced Cement concrete (RCC) without any insulation. The proposed insulated roof consists of three layers. The thickness of concrete (RCC) roof is about $12.5 \mathrm{~cm}$. On top of the RCC hemispherical shaped coconut shell are arranged in an array by keeping them upside down trapping the air inside it. The average height of the coconut shell is $6 \mathrm{~cm}$. Then the seashells are placed on top of the coconut shell to an average thickness of $2.5 \mathrm{~cm}$. Finally tiles are laid on top to protect them all from rainy weather condition.

\section{Experimental Work}

To analyze the thermal performance of the proposed insulation layer, two model rooms were constructed on top of the institute mechanical engineering department building. The temperatures at the interface were continuously sensed using RTD, thermocouples, etc. and recorded via data logger connected with computer system. A brief discussion of the instruments used for the experimental work and is as follows.

\section{Thermocouple}

A thermocouple is a temperature-measuring device consisting of two dissimilar metal conductors that are connected to each other at one or more spots. It induces a potential difference when the temperature of one of one junction differs from the reference junction temperature of the circuit. The conversion of temperature difference to electric current and vice-versa is termed as thermo-electric effect. Thermocouples are widely used type of temperature sensor for measurement and control, which converts a temperature gradient into change in electrical energy. Thermocouples are selfpowered and require no external form of excitation. Fig.2. depicts the working principle of thermocouple.

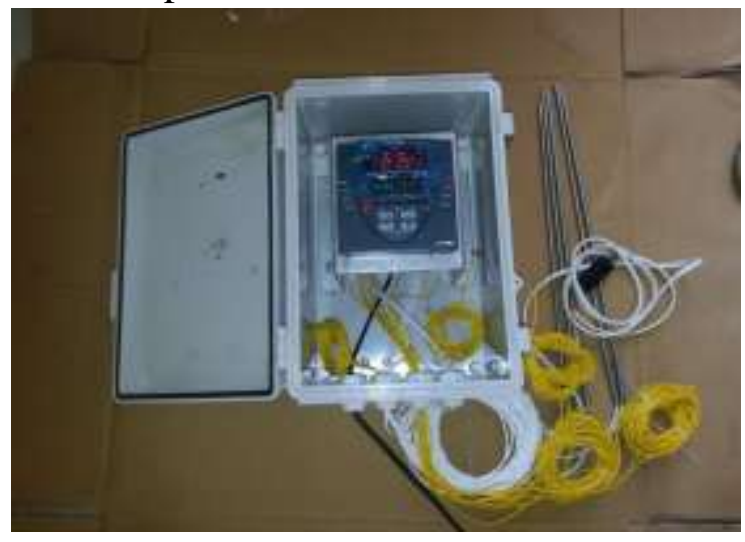

Fig.2 Block diagram showing the working Data Logger principle of thermocouple

A data logger (also data logger or data recorder) is an electronic device that records data over time or in relation to location either with a built in instrument or sensor or via external instruments and sensors. Increasingly, but not entirely, they are based on a digital processor (or computer). They generally are small, battery powered, portable, and equipped with a microprocessor, internal memory for data storage, and sensors. Some data loggers interface with a personal computer and utilize software to activate the data logger and view and analyze the collected data, while others have a local interface device (keypad, LCD) and can be used as a stand-alone device. Data loggers vary between general purpose types for a range of measurement applications to very specific devices for measuring in one environment or application type only. Data loggers are used in a broad range of indoor, outdoor and underwater environments - essentially anywhere data is needed and the convenience of battery power is preferred. One ofthe primary benefits of using data loggers is the ability to automatically collect data on a 24-hour basis fig. 3 shows the data logger for this project. 


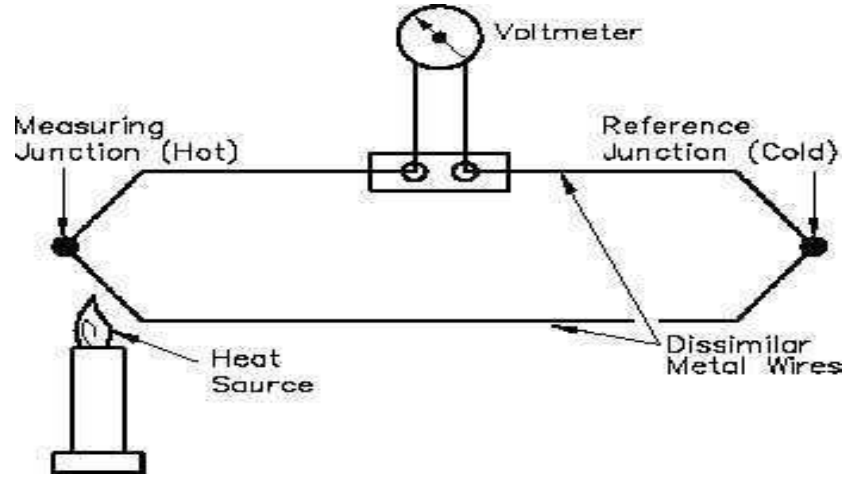

Fig.3 Digital photography of the data logger used in this experiment

Resistance Temperature Detectors:

An RTD (resistance temperature detector) is a temperature sensor that operates on the measurement principle that a material's electrical resistance changes with respect to temperature. Fig.4. shows the RTD used in this project. The relationship between an RTD's resistance and the surrounding temperature is highly predictable, allowing for accurate and consistent temperature measurement. By supplying an RTD with a constant current and measuring the resulting voltage drop across the resistor, the RTD's resistance can be calculated, and the temperature can be determined. Different materials used in the construction of RTD's offer a different relationship between resistance and temperature. These materials have a predictable change in resistance as the temperature changes; it is this predictable change that is used to determine temperature. Temperature sensitive materials used in the construction of RTD's include platinum, nickel, and copper; platinum being the most commonly used.

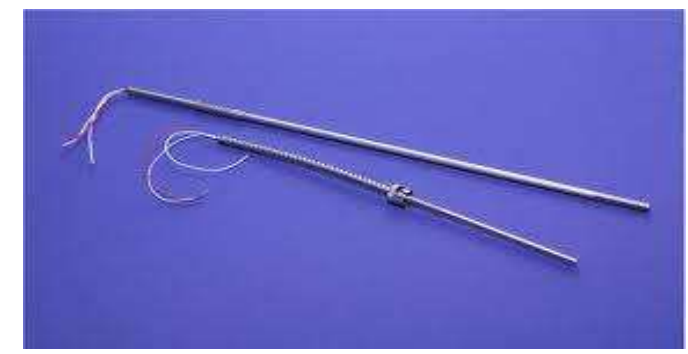

Fig.4 Temperature sensitive materials used in the construction of RTD's

The major limitation of RTD is, they are rarely used above $660{ }^{\circ} \mathrm{C}$. At temperatures above $660{ }^{\circ} \mathrm{C}$ it becomes increasingly difficult to prevent the platinum from becoming contaminated by impurities.

Experimental Rooms:

Two rooms having same dimension, orientation, and specification was constructed on the top floor of mechanical engineering department as shown in Fig.5. The dimension of the rooms are $1 \mathrm{~m} \times 1 \mathrm{~m} \times 1 \mathrm{~m}$ which is the length, breadth and height respectively. The roof of these two rooms were constructed using reinforced cement concrete (RCC) by conventional methods. One side of the room is kept open for airflow and it will resemble a door opening of a normal building.

The innovative thermal insulation shown in fig5. was on the top of one roof and another roof top was kept as such only with conventional concrete roof (i.e. without insulation).

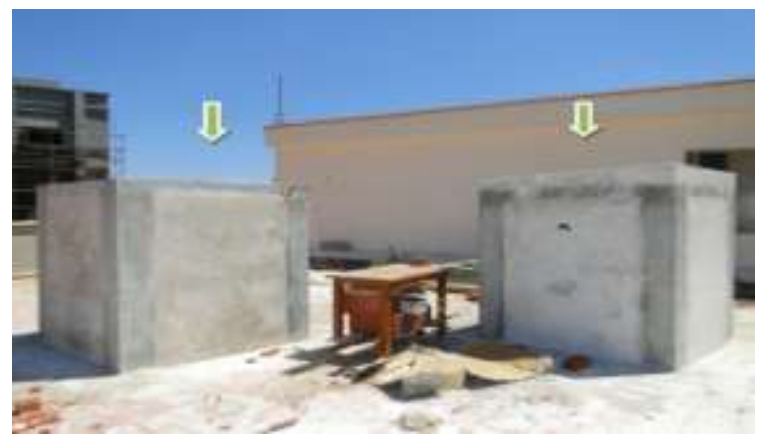

Fig.5. Identical Experimental Rooms for analysing the thermal interference

Thermocouples and resistance thermometers were fitted on both the rooms for observing the temperature between each layer. Air temperatures inside the rooms are monitored and recorded using resistance thermometers and thermocouples. Thermocouples and resistance thermometer were connected to Data Logger which has 16 channels input provision for connecting to the temperature measuring devices and by that way the temperature data can be logged by the logger into a hard drive of a computer.

\section{Data Logger Channels:}

Thermocouples and resistance temperature diodes are connected to the data logger channels and the channel number is set on the computer as per the channel diagram. The channels represent the 
temperature of each of the thermocouples. Thermocouples are fitted on every node of the insulated concrete roof and conventional concrete roof. The following table shows the representation of channels.

\section{References:}

[1] Ahmad Okeil (2010), "A holistic approach to energy efficient building forms", Energy and Buildings, Vol. 42 pp. 1437-1444.

[2] Bjørn Petter and Jelle (2010), "Traditional, state-of-the-art and future thermal building insulation materials and solutions - Properties, requirements and Possibilities". Energy and Buildings, Vol. 43 pp. 2549-2563.

[3]. Chau C.K., Tse M.S., and Chung K.Y. (2010), "A choice experiment to estimate the effect of green experience on preferences and willingness to-pay for green buildings",

[4]. Vulnerabilities by TeShun Chou, Department of Technology Systems, East Carolina University, Greenville, NC, U.S.A , International Journal of Computer Science \& Information Technology (IJCSIT) Vol 5, No 3, June 2013.

[5] An analysis of security issues for cloud computing by Keiko Hashizume, David G. Rosado , Eduardo Fernandez-Medina , Eduardo B Fernandez , Journal of Internet Services and Applications,2013 . 